\title{
A CADAVERIC STUDY ON DIVISION OF SCIATIC NERVE TO ACHIEVE ITS COMPLETE NERVE BLOCKAGE
}

\author{
M. Kapil Dev ${ }^{1}$, V.R.Jayakumar $* 2$.

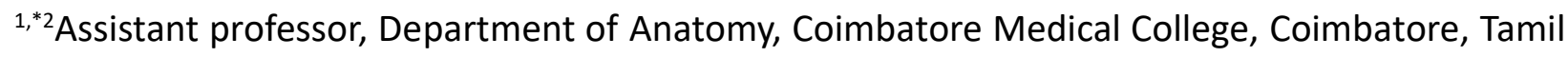 \\ Nadu, India.
}

\section{ABSTRACT}

Background: The sciatic nerve arises within the pelvis from the sacral plexus, enters into the gluteal region through the greater sciatic notch and divides into two terminal branches at variable level in the posterior compartment of thigh. The variable level of division of sciatic nerve in the thigh leads to failure of sciatic nerve blockage. Considering this clinical problem, the present study has been undertaken with the object to measure the distance of division of sciatic nerve from the popliteal crease.

Materials and Methods: 32 embalmed formalin fixed cadavers were dissected in the gluteal region, back of thigh and popliteal fossa and the sciatic nerve were exposed and the distance of division of sciatic nerve were measured from the popliteal crease.

Results: Out of 32 cadavers dissected the sciatic nerve divides at a distance range of $5 \mathrm{~cm}-20 \mathrm{~cm}$ in male cadavers and $4 \mathrm{~cm}-11 \mathrm{~cm}$ in female cadavers. In 2 cadavers the sciatic nerve divides within the pelvis itself.

Conclusion: So, to achieve complete blockage of sciatic nerve in most of the patients the needle should be inserted about $14 \mathrm{~cm}$ (mean distance) above the popliteal crease in males and $8 \mathrm{~cm}$ (mean distance) above the popliteal crease in females.

KEY WORDS: Sciatic nerve, Popliteal crease, Tibial nerve, Common peroneal nerve.

Address for Correspondence: Dr.V.R.Jayakumar, MD, Assistant professor, Department of Anatomy, Coimbatore medical college, Coimbatore, Tamil Nadu, India.

E-Mail: drjk.kimsanat@gmail.com

Access this Article online

Quick Response code

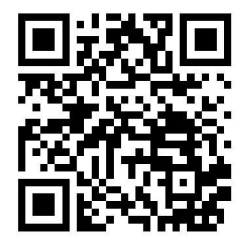

DOI: $10.16965 /$ ijar.2019.172

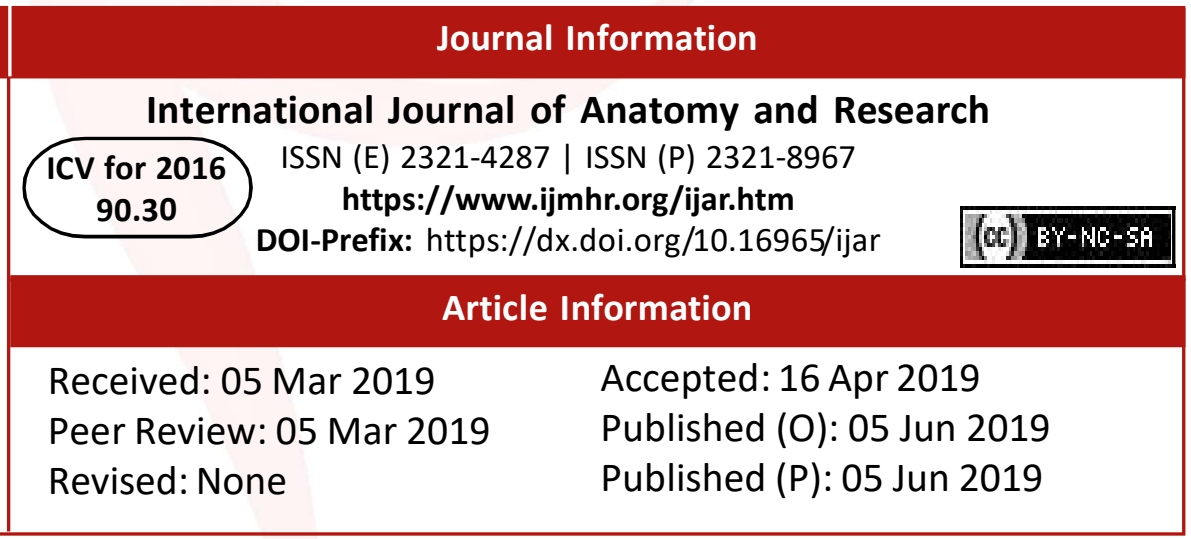

\section{INTRODUCTION}

The sciatic nerve is derived from sacral plexus as its terminal branch from $\mathrm{L}_{4}, \mathrm{~L}_{5}, \mathrm{~S}_{1}, \mathrm{~S}_{2}, \mathrm{~S}_{3}$ roots. It consists of two components named tibial and common peroneal components. Both the components are enclosed within a single epineural sheath and emerges out of the pelvis through the greater sciatic notch; in the gluteal region the nerve descends between the ischial tuberosity and the greater trochonter to enter the thigh deep to long head of biceps femoris. In the thigh the two components of the sciatic nerve divides at various distance from the popliteal crease into tibial andcommon peroneal nerves $[1,2]$. Along its course the sciatic nerve forms the major nerve supply to posterior compartment of thigh and also it plays a major role to supply the muscle and most of the cutaneous innervation of leg and foot via tibial and common peroneal nerve. In case of any surgeries done in lower part of leg and foot, the sciatic nerve blockage is done by anaesthetist in the popliteal fossa. Since the sciatic nerve divides at a 
M. Kapil Dev, V.R.Jayakumar. A CADAVERIC STUDY ON DIVISION OF SCIATIC NERVE TO ACHIEVE ITS COMPLETE NERVE BLOCKAGE.

variable level, it leads to failure or incomplete blockage of the nerve in the popliteal fossa. So the present study has been undertaken in order to access the level of division of sciatic nerve in order to improve the accuracy of the nerve blockage during surgeries on the leg and foot.

Objective:The present study is aimed to study the variations in the level of division of sciatic nerve into its two terminal branches to achieve complete sciatic nerve blockage in majority of patients during surgeries on the lower limb.

\section{MATERIALS AND METHODS}

The present study has been undertaken in Department of Anatomy at Coimbatore medical college,Coimbatore during the academic years 2016-17 to 2018-19. In this study totally 32 formalin fixed embalmed cadavers ( 23 male and 9 female cadavers) were used. In each cadaver the right and left lower limbs were dissected in gluteal region, back of thigh and popliteal fossa using routine dissection method [3]. So totally 46 male and 18 female specimens were dissected. After exposing the sciatic nerve in these regions, the level of division of sciatic nerve into its two subdivisions were measured from the popliteal crease and the results were noted. These results were compared between right and left sides of male cadavers with the right and left sides of female cadavers.

Fig. 1: Picture showing both the components of the sciatic nerve emerges below the piriformis muscle.

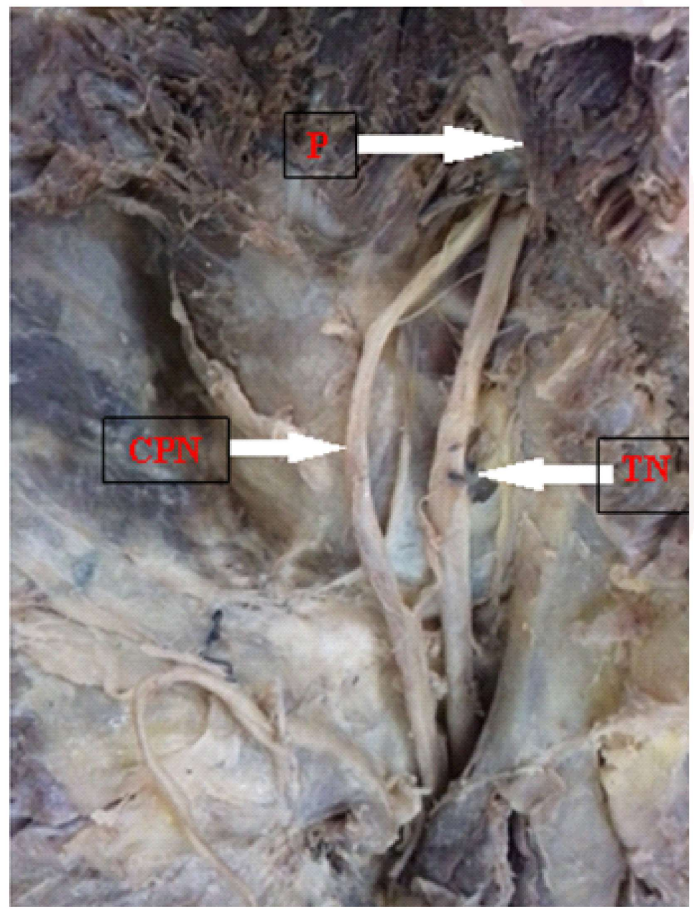

Fig. 2:Picture showing tibial component of sciatic nerve emerges below the piriformis and the common peroneal component emerges by piercing the substance of piriformis.

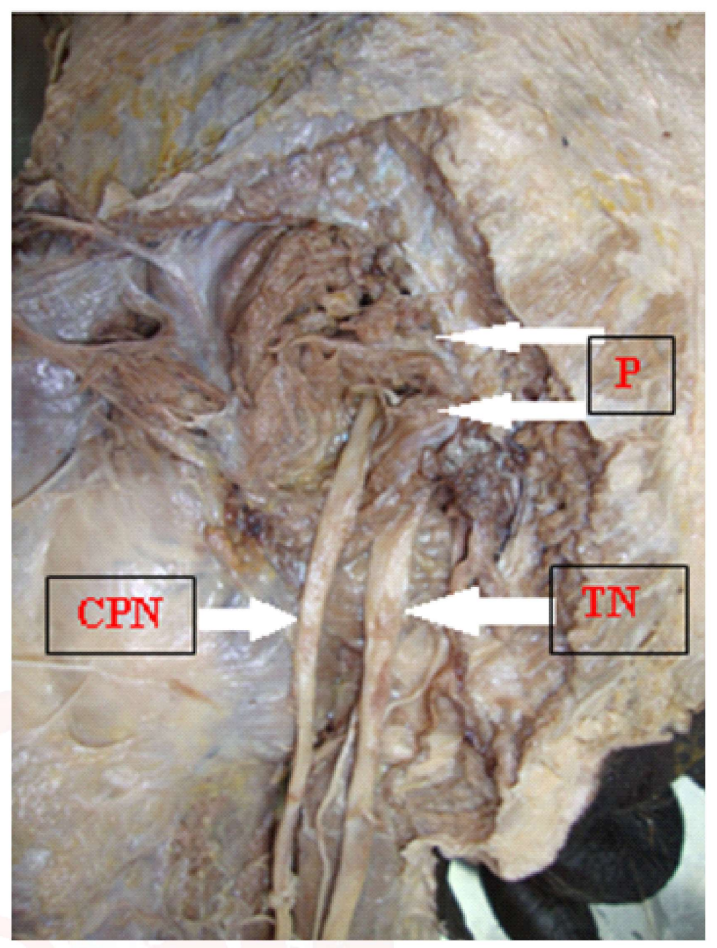

\section{RESULTS}

Out of 46 male specimens the mean distance of the division of sciatic nerve from the popliteal crease on the right side was $13.59 \mathrm{~cm}$ with standard deviation of $10.7 \mathrm{~cm}$ and on the left side was $13.44 \mathrm{~cm}$ with standard deviation of $11.11 \mathrm{~cm}$. Out of 18 female specimens the mean distance between popliteal fossa crease and the division of sciatic nerve was $7.55 \mathrm{~cm}$ with standard division of $1.74 \mathrm{~cm}$ and $7.22 \mathrm{~cm}$ with standard deviation of $2.18 \mathrm{~cm}$ respectively on right and left side.

Out of the 32 cadavers dissected, in most of the cadavers the sciatic nerve divides into tibial nerve and common peroneal nerve in the thigh; but in 2 cadavers (both on right and left side) the sciatic nerve divides within the pelvis itself. While dividing within the pelvis in one male cadaver the two components of the sciatic nerve emerges below the piriformis muscle on both right and left lower limbs and the two components does not join with each other in the rest of its course. In the other specimen the tibial component of sciatic nerve emerges below the piriformis and the common peroneal component emerges by piercing the piriformis muscle. 
Table 1:Mean distance of level of distance of sciatic nerve from the popliteal crease.

\begin{tabular}{|c|c|c|}
\hline & $\begin{array}{c}\text { Right side } \\
\text { (mean distance } \pm \text { standard } \\
\text { deviation) }\end{array}$ & $\begin{array}{c}\text { Left side } \\
\text { (mean distance } \pm \text { standard } \\
\text { deviation) }\end{array}$ \\
\hline Male & $13.59 \mathrm{~cm} \pm 10.7 \mathrm{~cm}$ & $13.44 \mathrm{~cm} \pm 11.11 \mathrm{~cm}$ \\
\hline Female & $7.55 \mathrm{~cm} \pm 1.74 \mathrm{~cm}$ & $7.72 \mathrm{~cm} \pm 2.18 \mathrm{~cm}$ \\
\hline
\end{tabular}

Table 2:Comparison of mean distance of level of division of sciatic nerve from the popliteal crease.

\begin{tabular}{|c|c|c|}
\hline & $\begin{array}{c}\text { Present study } \\
\text { (mean distance } \pm \text { standard } \\
\text { deviation) }\end{array}$ & $\begin{array}{c}\text { H.A.M. Saleh et al 2009 [4] } \\
\text { (mean distance } \pm \text { standard } \\
\text { deviation) }\end{array}$ \\
\hline Male right side & $13.59 \mathrm{~cm} \pm 10.7 \mathrm{~cm}$ & $84.5 \mathrm{~cm} \pm 4.31 \mathrm{~cm}$ \\
\hline Male left side & $13.44 \mathrm{~cm} \pm 11.11 \mathrm{~cm}$ & $83.3 \pm 3.98 \mathrm{~cm}$ \\
\hline Female right side & $7.55 \mathrm{~cm} \pm 1.74 \mathrm{~cm}$ & $78.5 \mathrm{~cm} \pm 7.87 \mathrm{~cm}$ \\
\hline Female left side & $7.72 \mathrm{~cm} \pm 2.18 \mathrm{~cm}$ & $79.2 \mathrm{~cm} \pm 7.21 \mathrm{~cm}$ \\
\hline
\end{tabular}

\section{DISCUSSION}

The sciatic nerve which is also called as ischiadic nerve is forming the major nerve supply to the posterior compartment of thigh, most of the leg and foot. So the sciatic nerve is commonly blocked by anaesthetist during surgeries in the leg and to relieve postoperative pain in the lower limb. Sometimes the anaesthetists experience an incomplete blockage of the nerve in some patients due to variations in the level of division of sciatic nerve.

In the present study, the level of division of sciatic nerve was measured and compared between right and left lower limbs of 32 embalmed cadavers. Out of 23 male cadavers dissected, the division of sciatic nerve from the popliteal crease do not differ significantly between right and left lower limbs with the $p$ value of 0.965 using student $t$ test with mean difference of 0.143 at $95 \%$ confidence interval of -6.3 to 6.6 .

Likewise, in 9 female cadavers also the level of division of sciatic nerve donot differ significantly between right and left side with $p$ value of 0.860 using student $t$ test with mean difference of 0.167 at $95 \%$ confidence interval of -2.13 to 1.80 .

The mean distance of level of division of sciatic nerve in male cadavers on right and left side is $13.59 \mathrm{~cm}$ with standard deviation $10.7 \mathrm{~cm}$ and $13.44 \mathrm{~cm}$ with standard deviation $11.11 \mathrm{~cm}$ respectively. Whereas in the female cadavers the mean distance is $7.55 \mathrm{~cm}$ with standard deviation $1.74 \mathrm{~cm}$ and $7.72 \mathrm{~cm}$ with standarddeviation $2.18 \mathrm{~cm}$ on right and left side respectively.

In a study done by H.A.M. Sale et.al the mean distance of the sciatic nerve bifurcation in male right and left lower limb was $8.45 \mathrm{~cm} \pm$ SD 3.98 $\mathrm{cm}$ and $83.3 \mathrm{~cm} \pm$ SD $3.98 \mathrm{~cm}$ respectively and in females $78.5 \mathrm{~cm} \pm S D 7.87 \mathrm{~cm}$ and $79.2 \mathrm{~cm}$ \pm SD $7.21 \mathrm{~cm}$ respectively $[3,4]$.

In the present study in two male cadavers the sciatic nerve divides into its two components within the pelvis itself. Out of these two cadavers, in one cadaver both the components of the sciatic nerve emerge out of the pelvic cavity below the piriformis muscle. In another cadaver the tibial component of the nerve emerges below the piriformis and the common peroneal component emerges by piercing the substance of the piriformis muscle.

In a study done by EwaOkraszewska et al noticed two variants of sciatic nerve in relation to the piriformis muscle. In one variant the sciatic nerve emerges below the piriformis muscle (Either as a single trunk or both the two component). In another variant the entire sciatic nerve or atleast a part of the nerve did not emerges below the piriformis muscle [5-7].

\section{CONCLUSION}

So, while doing the sciatic nerve blockage the anaesthetist should enter the needle about 14 $\mathrm{cm}$ above the popliteal crease in males and about $8 \mathrm{~cm}$ above the popliteal crease in females. This will block the sciatic nerve in majority of the patients. But the anaesthetist should also think about the division of sciatic 
nerve within the pelvis itself as a possible cause of failure or incomplete blockage of sciatic nerve. In such cases the anaesthetist should think of double injection technique for both tibial nerve and common peroneal nerve separately to achieve the goal.

\section{ABBREVIATIONS}

P - Piriformis

TN - Tibial nerve

CPN-Common peroneal nerve.

\section{Conflicts of Interests: None}

\section{REFERENCES}

[1]. Standring S Gray's Anatomy, $40^{\text {th }}$ edn. Pelvic girdle and lower limb: overview and Surface Anatomy, ELBS. Elsevier: Churchill Livingstone, 2008;1337$8 ; 1384$.

[2]. Datta A K. Essentials of human Anatomy, $4^{\text {th }}$ edn. Superior and Inferior extremities, Current books international: Kolkata, 2009;193.

[3]. Romanes G J Cunningham's Manual of Practical Anatomy. Vol 1, $15^{\text {th }}$ edn. New York, Oxford medical publications press Inc. 2011;153-62.
[4]. Saleh H A M et al. Anatomical variation of sciatic nerve division in the popliteal fossaand its implication in popliteal nerve blockage, Folia Morphal, 2009;68(4):256-9.

[5]. Ewaokraszewska et al. Sciatic nerve variations in some studies on the polish population and its statistical significance, Folia Morphal, 2002;61(4):27782.

[6]. NizankowskCz et al. Studies on the sciatic nerve course in man in the fetal period, Folia Morphal, 1979;31:507-13.

[7]. Babinski M A et al. A rare variation in the high division of the sciatic nerve surrounding the superior gemellus muscle, European journal of Morphology, 2003;41(1):41-2.

How to cite this article:

M. Kapil Dev, V.R.Jayakumar. A CADAVERIC STUDY ON DIVISION OF SCIATIC NERVE TO ACHIEVE ITS COMPLETE NERVE BLOCKAGE. Int J Anat Res 2019;7(2.3):6612-6615. DOI: 10.16965/ ijar.2019.172 